\title{
Article \\ Application of Artificial Neural Networks to Predict Insulation Properties of Lightweight Concrete
}

\author{
Marzena Kurpińska ${ }^{1, *(D)}$, Leszek Kułak ${ }^{2}$, Tadeusz Miruszewski ${ }^{2}$ and Marcin Byczuk $^{2}$ \\ 1 Faculty of Civil and Environmental Engineering, Gdańsk University of Technology, ul. Narutowicza 11/12, \\ 80-233 Gdańsk, Poland \\ 2 Faculty of Applied Physics and Mathematics, Gdańsk University of Technology, ul. Narutowicza 11/12, \\ 80-233 Gdańsk, Poland; leszek.kulak@pg.edu.pl (L.K.); tadeusz.miruszewski@pg.edu.pl (T.M.); \\ marcin.byczuk@pg.edu.pl (M.B.) \\ * Correspondence: marzena.kurpinska@pg.edu.pl
}

Citation: Kurpińska, M.; Kułak, L.;

Miruszewski, T.; Byczuk, M.

Application of Artificial Neural

Networks to Predict Insulation

Properties of Lightweight Concrete.

Appl. Sci. 2021, 11, 10544. https://

doi.org/10.3390/app112210544

Academic Editor: Panagiotis

G. Asteris

Received: 5 September 2021

Accepted: 4 November 2021

Published: 9 November 2021

Publisher's Note: MDPI stays neutral with regard to jurisdictional claims in published maps and institutional affiliations.

Copyright: (c) 2021 by the authors. Licensee MDPI, Basel, Switzerland. This article is an open access article distributed under the terms and conditions of the Creative Commons Attribution (CC BY) license (https:// creativecommons.org/licenses/by/ $4.0 /)$.

\begin{abstract}
Predicting the properties of concrete before its design and application process allows for refining and optimizing its composition. However, the properties of lightweight concrete are much harder to predict than those of normal weight concrete, especially if the forecast concerns the insulating properties of concrete with artificial lightweight aggregate (LWA). It is possible to use porous aggregates and precisely modify the composition of lightweight concrete (LWC) with specific insulating properties. In this case, it is advisable to determine the parameters of the components and perform preliminary laboratory tests, and then use theoretical methods (e.g., artificial neural networks (ANNs) to predict not only the mechanical properties of lightweight concrete, but also its thermal insulation properties. Fifteen types of lightweight concrete, differing in light filler, were tested. Lightweight aggregates with different grain diameters and lightweight aggregate grains with different porosity were used. For the tests, expanded glass was applied as a filler with very good thermal insulation properties and granulated sintered fly ash, characterized by a relatively low density and high crushing strength in the group of LWAs. The aim of the work is to demonstrate the usefulness of an ANN for the determination of the relationship between the selection of the type and quantity of LWA and porosity, density, compressive strength, and thermal conductivity (TC) of the LWC.
\end{abstract}

Keywords: artificial neural networks; thermal conductivity; lightweight concrete; lightweight aggregate; predicting properties

\section{Introduction}

Lightweight cement composites, as well as lightweight concrete (LWC), are a group of materials with an increasing demand in construction. LWC has a lower density and a lower coefficient of thermal conductivity than ordinary concrete [1]. In order to obtain sufficiently high strength of LWC as a construction material, its composition can be modified [2-4].

Due to the tendency to reduce $\mathrm{CO}_{2}$ emissions, especially in countries where building heating is needed, more and more requirements regarding thermal insulation for external walls are being introduced. On the other hand, in countries where the air temperature remains high and air-conditioning units are in extensive use, the same LWC material solutions can reduce heat transfer into the building interior $[5,6]$. Therefore, there is an increasing demand for construction materials with high thermal insulation and relatively high compressive strength at the same time [7,8]. All over the world, research is conducted on the modification of LWC properties to create positive impact on the environment. To improve thermal insulation properties of buildings, the origin and properties of LWA used for the production of LWC should be taken into account $[9,10]$. LWA may be of natural origin, such as pumice or fired clay, and may be produced artificially from waste, such as fly ash, sewage sludge, or glass cullet. The properties of artificial LWAs can vary considerably 
depending on the origin of the main waste material used in their composition and the way in which it is processed. Until recently, LWC design relied heavily on the knowledge and experience of LWA and concrete producers, as it is difficult to recreate conditions, similar to those on the actual construction site, in the laboratory [11,12]. However, increasing research capabilities allow for the precise determination both of the very properties of LWA and for the simulation of conditions close to the environment (high or low temperatures) and to update our knowledge about the properties of LWC $[13,14]$.

The authors of this publication focused mainly on the possibility of using a ready mix of LWA: granulated expanded glass (GEGA) and sintered fly ash (GAA). GEGA, classified as a lightweight material, is appreciated for its low density and much higher thermal insulation than normal weight concrete (NWC) with natural aggregate [15]. GAA, on the other hand, is characterized by high compressive strength. The use of two types of the aggregates with different properties in different proportions allows modeling of LWC properties in terms of density, compressive strength and thermal conductivity [16]. Experimental and analytical-experimental design methods are used to determine the effect of the components used on the characteristics of the LWC mixture. The laboratory tests require high level of researchers' involvement, they are time-consuming and therefore costly. Moreover, in order to obtain the desired effect, whether in terms of specific density, strength or thermal insulation, the tests must be repeated many times. The tests should also be repeated in the event of change in the type or quality of the main components of mix concrete [17]. ANN can be used to predict output data based on a defined set of input data as the authors of the works show [17-20]. The main aim of the work was to present a proposed application for the use of ANN to forecast mechanical properties and thermal conductivity in correlation with porosity and density of LWC depending on the mixing ratio of GEGA and GAA.

The main benefit of using computer technology with an ANN testing method to solve a predetermined problem is that there is no need to derive mathematical dependencies, because in the process of ANN learning, appropriate values are assigned to subsequent variables, and then the solution obtained in the process of experimental research is implemented [21,22]. In the presented work, the results of LWC tests, obtained earlier in the laboratory, were analyzed. The LWC samples were made with the addition of granulated expanded glass (GEGA) and sintered fly ash (GAA). Laboratory experiments and the analysis of the test results have shown, that the use theoretical tools proves to be particularly helpful to predict LWC properties if we use a mix of aggregates in different proportions $[18-20,23,24]$. It is also possible to precisely determine the composition of the aggregate mixture, so that it is possible to obtain LWC with the desired properties such as density, compressive strength, and thermal insulation. Estimating the share of individual types and sizes of the aggregates with the use of ANN requires a significant number of repetitions in order to train the network.

\section{Materials and Methods}

\subsection{Materials}

Following [25], CEM I 42.5R cement was used to perform the tests. The chemical composition of cement: $\mathrm{CaO}-63.5 \%, \mathrm{SiO}_{2}-21.5 \%, \mathrm{Al}_{2} \mathrm{O}_{3}-6.1 \%, \mathrm{Fe}_{2} \mathrm{O}_{3}-3.3 \%, \mathrm{SO}_{3}-2.9 \%$, $\mathrm{MgO}-1.1 \%$. Blaine fineness- $3384 \mathrm{~cm}^{2} / \mathrm{g}$ and water demand- $27 \%$. Compressive strength of cement in 28 days- $57.4 \mathrm{MPa}$.

The properties of LWA used in the tests are shown in Figure 1. The chemical properties of LWA are GEGA: $\mathrm{SiO}_{2}-63.3 \%, \mathrm{CaO}-14.2 \%, \mathrm{Na}_{2} \mathrm{O}-13.4 \%, \mathrm{MgO}-3.0 \%, \mathrm{Al}_{2} \mathrm{O}_{3}-0.7 \%$, loss on ignition- $4.5 \%$ and $\mathrm{GAA}: \mathrm{SiO}_{2}-52.8 \%, \mathrm{Al}_{2} \mathrm{O}_{3}-24.3 \%, \mathrm{Fe}_{2} \mathrm{O}_{3}-7.5 \%, \mathrm{CaO}-4.5 \%$, $\mathrm{MgO}-3.2 \%$, and loss on ignition at $7.1 \%$. The physical properties of LWA are presented in Table 1. The grain of GAA sintered ash with a diameter of $8 \mathrm{~mm}$ are characterized by similar porosity, but 4 times higher density than the grain of foamed aggregate. The crushing strength of GAA aggregate grain is up to $25 \%$ higher, which is important when modifying the LWC in terms of compressive strength. The subsurface zone of GEGA and 
GAA grains is characterized by an open structure. While the ingredients are mixing, the open pores are being filled with cement paste. If the correct amount of binder is used, this property can positively influence the final mechanical properties of the LWC.

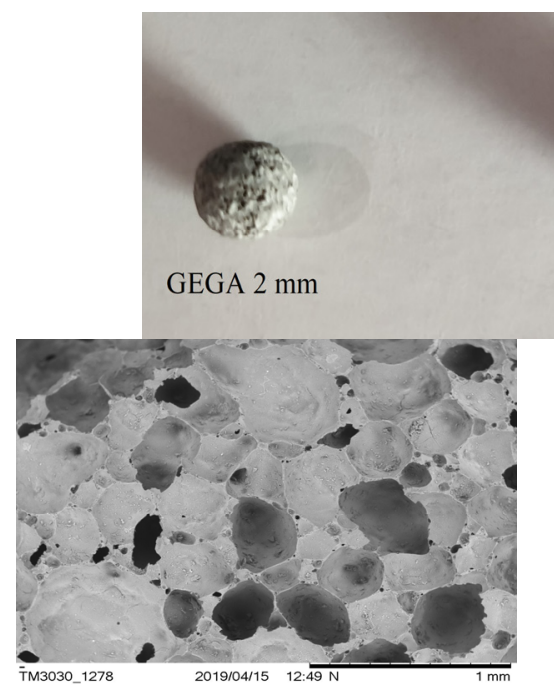

(a) GEGA $2 \mathrm{~mm}$

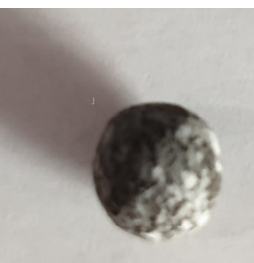

GEGA 4 mm

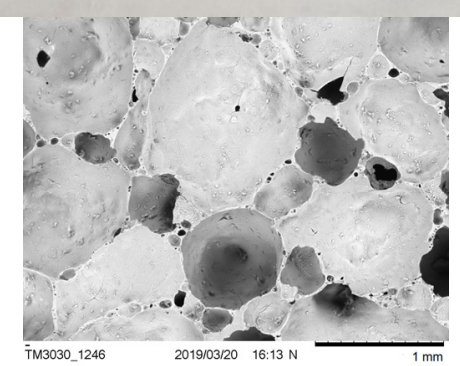

(b) GEGA $4 \mathrm{~mm}$
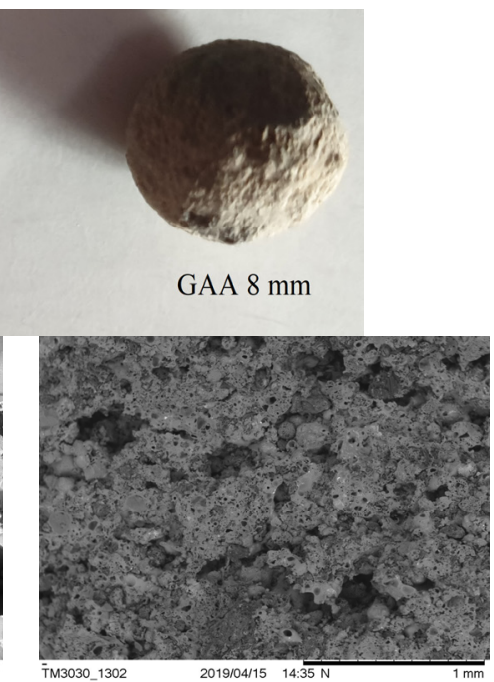

(c) GAA $8 \mathrm{~mm}$

Figure 1. Structure of the LWA used in the tests.

Table 1. Physical properties of LWA.

\begin{tabular}{|c|c|c|c|c|c|}
\hline & Water Absorption WA 24 & Volume Density $\rho_{a}$ & Open Porosity $p_{o}$ & Pore Radius & Pore Volume \\
\hline & $(\%)$ & $\left(\mathrm{kg} / \mathrm{m}^{3}\right)$ & $(\%)$ & $(\mathrm{nm})$ & $\left(\mathrm{cm}^{3} / \mathrm{g}\right)$ \\
\hline GEGA $2 \mathrm{~mm}$ & 15.2 & 380 & 37 & $1.55-3.71$ & $1.02-7.56 \times 10^{-3}$ \\
\hline GEGA $4 \mathrm{~mm}$ & 17.8 & 350 & 42 & $1.69-3.70$ & $1.25-8.54 \times 10^{-3}$ \\
\hline GAA $8 \mathrm{~mm}$ & 16.5 & 1350 & 37 & $1.32-2.83$ & $0.99-6.67 \times 10^{-3}$ \\
\hline
\end{tabular}

\subsection{Concrete Mix}

The research project was divided into successive stages: 15 LWC mixes were designed with different proportions of GEGA $2 \mathrm{~mm}$, GEGA $4 \mathrm{~mm}$ and GAA $8 \mathrm{~mm}$, then the mixes were prepared, and the rheological properties of the mixes were tested. Then, the physical properties of the LWC in terms of porosity and density of the LWC as well as compressive strength and thermal conductivity were determined. The aim of the research was to determine the dependence of the use of LWA with known porosity and density on the physical properties of the LWC. The obtained results were used to predict the LWC properties using ANN. The composition of the mixtures is presented in Table 2. The tested aggregate was not pre-wetted. The natural humidity of the aggregates was tested before making the mixtures and was, respectively: GEGA $2 \mathrm{~mm}(3.4 \%)$, GEGA $4 \mathrm{~mm}(2.9 \%)$, and GAA 8 $\mathrm{mm}(4.1 \%)$. The total amount of water in the mixes was corrected for the amount of water contained in the aggregates. A constant water/cement $(\mathrm{w} / \mathrm{c})$ ratio of 0.5 was maintained. No chemical admixtures or additives were used in preparation of LWC mixtures.

\subsection{Methods}

The concrete mix components were mixed in a mechanical mixer with a planetary structure. The following sequence of dosing the ingredients was used: first, the cement and part of the mixing water (approx. 75\%) were mixed for $2 \mathrm{~min}$, and then GAA $8 \mathrm{~mm}$, GEGA $4 \mathrm{~mm}$ and GEGA $2 \mathrm{~mm}$ were successively added to the cement grout in the amount according to the design given in Table 2. The mixture was mixed for another 2 min adding the remaining makeup water (20-25\%) until the desired consistency (S3) was obtained in 
accordance with [26]. The consistency of concrete mixes was measured according to [27] the slump method. The consistency was in the $\mathrm{S} 3$ range $(100-150 \mathrm{~mm})$ for all mixes, with the exception of LWC 15 for which the range consistency was in the S2 $(50-90 \mathrm{~mm})$. The test specimens were made in accordance with [28] in the amount given in the Table 3.

Table 2. Details of LWC mix proportions.

\begin{tabular}{|c|c|c|c|c|c|c|c|c|c|c|c|c|c|c|c|c|}
\hline LWC & & 1 & 2 & 3 & 4 & 5 & 6 & 7 & 8 & 9 & 10 & 11 & 12 & 13 & 14 & 15 \\
\hline \multirow{2}{*}{ GEGA 2 mm } & $(\%)$ & 0 & 25 & 50 & 75 & 0 & 0 & 25 & 25 & 25 & 50 & 50 & 0 & 0 & 75 & 100 \\
\hline & $\left(\mathrm{kg} / \mathrm{m}^{3}\right)$ & 0 & 65 & 130 & 195 & 0 & 0 & 65 & 65 & 65 & 130 & 130 & 0 & 0 & 195 & 260 \\
\hline \multirow{2}{*}{ GEGA 4 mm } & $(\%)$ & 0 & 0 & 0 & 0 & 100 & 75 & 50 & 25 & 75 & 50 & 25 & 50 & 25 & 25 & 0 \\
\hline & $\left(\mathrm{kg} / \mathrm{m}^{3}\right)$ & 0 & 0 & 0 & 0 & 240 & 180 & 120 & 60 & 180 & 120 & 60 & 120 & 60 & 60 & 0 \\
\hline \multirow{2}{*}{ GAA $8 \mathrm{~mm}$} & $(\%)$ & 100 & 75 & 50 & 25 & 0 & 25 & 25 & 50 & 0 & 0 & 25 & 50 & 75 & 0 & 0 \\
\hline & $\left(\mathrm{kg} / \mathrm{m}^{3}\right)$ & 580 & 435 & 290 & 145 & 0 & 145 & 145 & 290 & 0 & 0 & 145 & 290 & 435 & 0 & 0 \\
\hline CEM I 42.5R & $\left(\mathrm{kg} / \mathrm{m}^{3}\right)$ & \multicolumn{15}{|c|}{500} \\
\hline water & $\left(\mathrm{kg} / \mathrm{m}^{3}\right)$ & \multicolumn{15}{|c|}{250} \\
\hline water/cement & $(-)$ & \multicolumn{15}{|c|}{0.5} \\
\hline
\end{tabular}

Table 3. The specimens for testing.

\begin{tabular}{|c|c|c|c|}
\hline Test & Specimen's Size (cm) & $\begin{array}{l}\text { Quantity of the Specimens } \\
\text { (Pieces) }\end{array}$ & $\begin{array}{c}\text { Total Specimens' Quantity } \\
\text { (Pieces) }\end{array}$ \\
\hline Volume density in a & $10 \times 10 \times 10$ & 3 & 45 \\
\hline dry state & $2 \times 2 \times 2$ & 3 & 45 \\
\hline $\begin{array}{c}\text { Compressive strength at } \\
28 \text { days }\end{array}$ & $0.15 \times 0.15 \times 0.15$ & 6 & 90 \\
\hline Porosity & $0.10 \times 0.10 \times 0.10$ & 3 & 45 \\
\hline Thermal conductivity & $0.245 \times 0.245 \times 0.04(1 \times w \times t)$ & 3 & 45 \\
\hline
\end{tabular}

LWC tests were performed after 28 days. The LWC density was tested by the Archimedes method using three $2 \times 2 \times 2 \mathrm{~cm}$ samples were cut out from each LWC 1-15 variant. The first stage was to measure the mass of the dry sample $\left(m_{s}\right)$. The samples were then saturated with a liquid of known density in a vacuum desiccator up to fill all the concrete pores. The standard liquid was deionized water $\left(\rho=1 \mathrm{~g} / \mathrm{cm}^{3}\right)$ and kerosene $\left(\rho=0.8241 \mathrm{~g} / \mathrm{cm}^{3}\right)$, depending on the composition of the tested LWC. Density $\left(\rho_{p}\right)$ was calculated according to the pattern (1) and porosity $\left(p_{0}\right)$ was calculated by means of the Equation (2):

$$
\begin{aligned}
\rho_{p} & =\frac{m_{s}}{\left(m_{n}-m_{w}\right) * d_{0}} \\
p_{o} & =\frac{m_{n}-m_{s}}{m_{n}-m_{w}} \cdot 100 \%
\end{aligned}
$$

where $\rho_{p}$-volume density, $\left(\mathrm{g} / \mathrm{cm}^{3}\right) ; m_{w}$-mass, saturated with the liquid, weighed in a liquid (water), (g); $m_{n}$-mass, saturated with the liquid, weighed in the air, $(\mathrm{g}) ; m_{s}$-mass, weighed in the air, $(\mathrm{g}) ; d_{0}$-liquid density in the tested temperature, $\left(\mathrm{g} / \mathrm{cm}^{3}\right)$.

The compressive strength was tested with an Advantest 9 (Controls-Manufacturer, Liscate, Milan Italy) machine with a maximum pressing force of $3000 \mathrm{kN}$ according to [29]. The compressive strength was determined as the arithmetic mean of the six results.

Thermal conductivity tests on concrete specimens were conducted by means of a PHYWE house model (PHYWE Systeme GmbH and Co., Göttingen, Germany). It consists of removable side walls and its purpose is to determine thermal conductivity of the speci- 
mens, made of different materials. Figure $2 \mathrm{a}, \mathrm{b}$ shows the construction of the house model. The chamber consists of thermally insulated base with a removable cover, measurement walls, inner insulation, heater. The floor of the base is insulated by means of the polystyrene plate, about $5 \mathrm{~cm}$ thick. Side walls with square holes $210 \times 210 \mathrm{~mm}$ are put inside and fixed with two screws at each side of the hole gasket. On the inner walls there is a rail with eccentric plates, used to fix additional outer insulation.

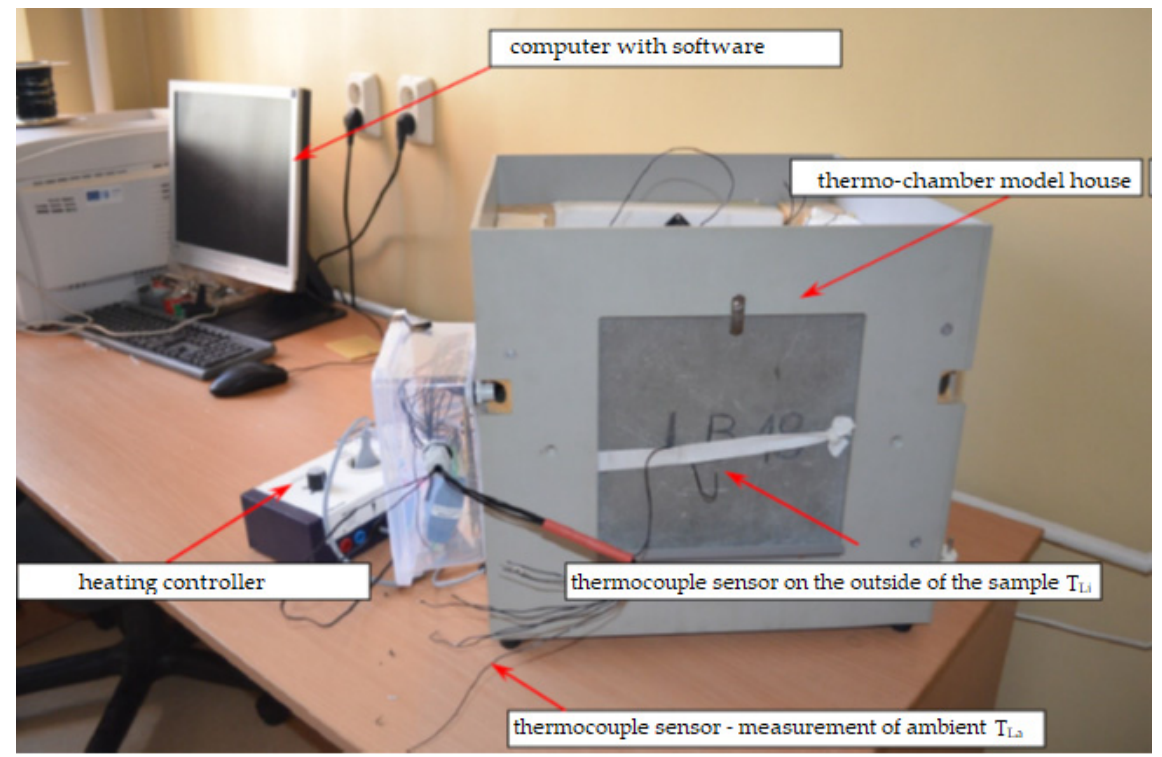

(a)

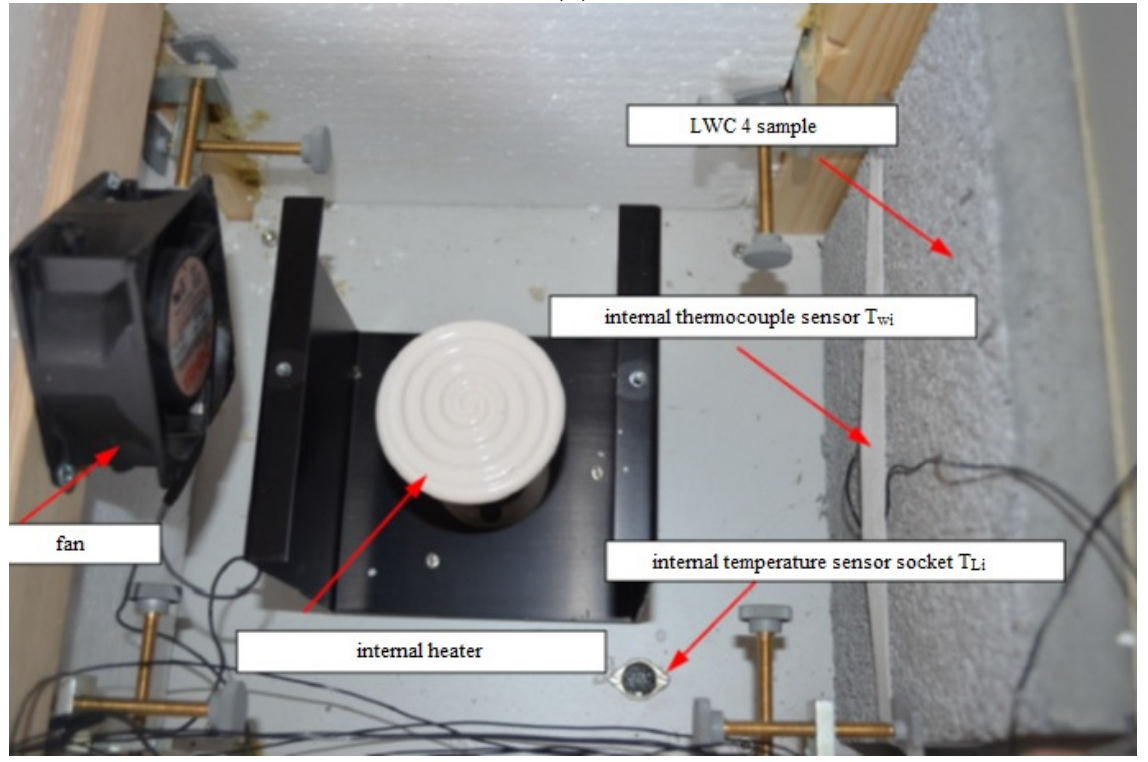

(b)

Figure 2. Model house construction: (a) outer elements; (b) inner elements.

Thermal conductivity coefficient $\lambda$ was calculated by means of inner and outer model house temperature measurement, and by measurement of the inner and outer wall temperature of the tested specimen. The temperature was measured each 10 min since establishing balance state on the sides of the specimen. Thermal balance on the walls of the specimen was achieved after 5-6 h, but to receive more detailed test results, the temperature was being measured for $8 \mathrm{~h}$ each $10 \mathrm{~min}$. Measurement results were recorded $T_{L i}, T_{w i}, T_{w a}$, and $T_{L a}$. Figure 3 shows the scheme of heat transfer through the element. 


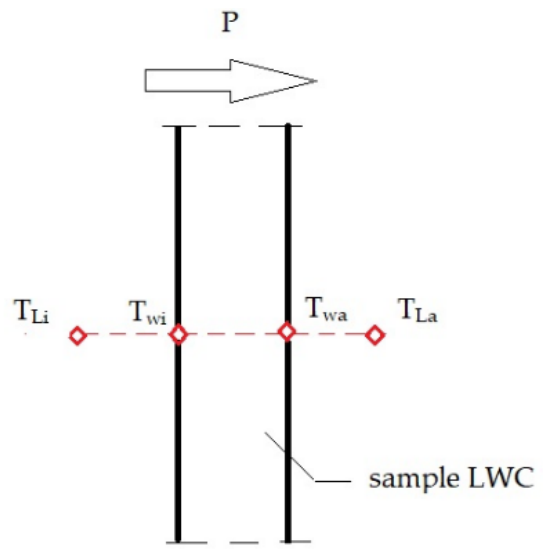

where:

$T_{L i}-$ chamber inner temperature $\left({ }^{\circ} \mathrm{C}\right)$;

$\mathrm{T}_{w i}$-specimen inner temperature $\left({ }^{\circ} \mathrm{C}\right)$;

$T_{w a}-$ specimen outer temperature $\left({ }^{\circ} \mathrm{C}\right)$;

$\mathrm{T}_{\mathrm{L} a}$-temperature of the model house surrounding $\left({ }^{\circ} \mathrm{C}\right)$;

$d$-specimen thickness $(\mathrm{cm})$;

$P$-heat transfer $(\mathrm{W})$.

Figure 3. Scheme of heat transfer through the element.

The scheme of heat transfer through the tested element of LWC 1-15 to the outer environment was calculated according to the pattern:

$$
P=\alpha_{i} \cdot A \cdot\left(T_{L i}-T_{w i}\right)
$$

and

$$
P=\alpha \cdot A \cdot\left(T_{w a}-T_{L a}\right)
$$

where:

$P$ - heat flow energy (W);

$\alpha_{i}$-air heat transfer coefficient of the inner specimen's wall;

$A$-specimen's cross section field $\left(\mathrm{cm}^{2}\right)$;

$\alpha=8.1 \mathrm{~W} / \mathrm{K} \cdot \mathrm{m}^{2}$-air heat transfer coefficient of the specimen's outer wall.

Thermal conductivity in the tested wall was calculated according to the pattern:

$$
P=\frac{\lambda}{d} \cdot A \cdot\left(T_{w i}-T_{w a}\right)
$$

where:

$\lambda$-thermal conductivity $(\mathrm{W} / \mathrm{Km})$;

$A$-specimen cross section field $\left(\mathrm{cm}^{2}\right)$;

$d$-specimen thickness $(\mathrm{cm})$.

Determining heat transfer coefficient:

$$
P=k \cdot A \cdot\left(T_{L i}-T_{\text {wa }}\right)
$$

where $k$ - heat transfer coefficient $\left(\mathrm{W} / \mathrm{Km}^{2}\right)$.

Heat transfer coefficient is expressed by the pattern:

$$
\frac{1}{k}=\frac{1}{\alpha_{1}}+\frac{d}{\lambda}+\frac{1}{\alpha}
$$


The specimens of the dimensions: $24.5 \times 24.5 \times 4.0 \mathrm{~cm}$ were used for the thermal conductivity test. The heat source was placed inside the device. The temperature on the inner and outer surface wall of each specimen was measured throughout the entire test time, and the air temperature was measured as well in each case. Since the temperature gradient could vary from the bottom to the top of the wall, it was necessary to perform all the measurements at the same height. Thermocouple for measurement of the inside temperature was placed $5 \mathrm{~cm}$ from the model house wall. The holes in the corner posts were used to place the thermocouple. To measure the temperature of the wall, the ends of the thermocouple had to be permanently fixed to the specimen's side wall as close as possible to the perpendicular axis of the specimen. The differences in the measurements are of the highest importance in the test results assessment, therefore, thermocouples must be checked accurately, and all deviations must be seriously considered in the process of the assessment of the results. $100 \mathrm{~W}$ source of heat was used for heating, and steady state temperature of the interior was kept by means of thermostat. The tested specimens were heated until the temperature balance on the inner and outer walls was achieved.

\subsection{Applications of ANN}

Based on literature analysis and research results [3,18-20,23,24,30-32], it is known ANNs in case of issue analysis, often give better results than analytical methods in which there are problems with prediction, classification of results or monitoring. The advantage of ANNs is their unique feature, which is the ability to learn and possibility generalize the acquired knowledge on the basis of even relatively small datasets. Compared to software that performs algorithmic data processing, for example, polynomial approximation, ANNs can reasonably generalize knowledge based on new input data, that were not known before, during the network training process. This property of ANNs results from their ability to approximate a sufficiently wide class of functions of several variables (e.g., continuous functions) [33-35]. An example of the use of ANN is the analysis of concrete properties. This method is especially useful for cases where the analytical description is difficult or impossible due to the large number of variables and the difficulty of their precise determination or measurement. In the present study, ANN was used to predict the properties of the LWC. LWC features such as density, porosity and compressive strength as well as thermal conductivity were analyzed for each mixture of three types of lightweight aggregates from $0 \%$ to $100 \%$ (with a $25 \%$ change): GEGA $2 \mathrm{~mm}$, GEGA $4 \mathrm{~mm}$, and GAA $8 \mathrm{~mm}$ using the authors' previous tests results [36]. In order to perform the ANN's learning process, the laboratory test data was divided into three separate datasets in which the training dataset it was $70 \%$ of the total number of cases, whereas the test dataset was $15 \%$ of the number of cases. The validation dataset it was $15 \%$ of the number of cases. As a result of such data division, by the learning process, through the appropriate adjustment of ANN weights, took place on a set of $85 \%$ of randomly selected experimental input data. The test dataset allowed to compare properties of LWC as compressive strength and thermal conductivity vs. porosity and density. A comparison was also possible properties obtained through research with the values predicted by the network, also when on which the ANN was not trained and validated. In ANN analysis, individual LWC 1-15 samples differed in the percentages of the individual LWAs. The shares of three different aggregates, i.e., GEGA $2 \mathrm{~mm}$, GEGA $4 \mathrm{~mm}$, and GAA $8 \mathrm{~mm}$ were a sum $100 \%$. The main assumption was, that there were two independent variables in the calculated examples, incl. the contents of GEGA $2 \mathrm{~mm}$ and GEGA $4 \mathrm{~mm}$. The GAA content is the remainder so that the sum of the percentages of all LWAs is $100 \%$.

For the purpose of a given task, we used the feedforward ANN with two hidden layers, two input neurons corresponding to the share of GEGA $2 \mathrm{~mm}$ and GEGA $4 \mathrm{~mm}$ and one output neuron corresponding to the predicted value e.g., density, porosity, compressive strength, or thermal conductivity. The connections between neurons were of "each other" type (full connection) and it were applied according to backward error propagation algorithm. The number of neurons in the first hidden layer varied from 2 to 12 and in the second 
hidden layer from 2 to 17, depending on the forecasted variable. Error function was a mean square error of ANN, and a sigmoid function was applied as function of neuron activation. The three-input dataset consisted of 15 measurement values as properties of LWC and was used to study the quality of prediction of LWC these features using ANN. The training data set for each predicted properties LWC, consisted of 13 randomly selected measurement values from among 15 values from the input dataset involving various content of GEGA $2 \mathrm{~mm}$ and GEGA $4 \mathrm{~mm}$. The other two values formed a testing data set. This procedure was repeated 10 times to obtain 10 different testing data sets using cross-validation. Based on the theorem that for a sigmoid activation function, any continuous function can be uniformly approximated, with any accuracy by means of a feedforward neural network containing two hidden layers the ANN with two hidden layers was trained by multiple feeding of the training dataset to the ANN's input, until the stabilization of the total mean square error of the network at a very low level while avoiding the phenomenon of ANN overfitting [30,35]. After the completed process of the ANN training, a test data set was given to the network input in order to assess the quality of a given network architecture. The relative error of ANN was calculated as the sum of the squares of differences between the laboratory results and those, predicted by the network.

The network architecture was selected on the basis of the $[35,37]$ theorem, there is an activation function $f$ of class $C^{\infty}$, strictly increasing, sigmoidal, with the following properties:

For any function $F \in C[0,1]^{n}$ and $\varepsilon>0$, there are constants $d_{i}, c_{i j}, \theta_{i j}, \gamma_{i}$ and vectors $\boldsymbol{w}_{i j} \in \mathbb{R}^{n}$, for which $\left|F(\boldsymbol{x})-\sum_{i=1}^{4 n+3} d_{i} f\left(\sum_{j=1}^{2 n+1} c_{i j} f\left(\boldsymbol{w}_{i j} \cdot \boldsymbol{x}_{i}+\theta_{i j}\right)+\gamma_{i}\right)\right|<\varepsilon$ for all $x \in[0,1]^{n}$.

In other words, for this specific (sigmoidal) activation function, any continuous function on a unit sample in $\mathbb{R}^{n}$ can be uniformly approximated with any accuracy by a neural network containing two hidden layers.

Given that the universal approximation theorems do not provide information on the number of neurons in the hidden layer needed to provide the desired accuracy, the ANN was first tested with two hidden layers containing a relatively large number of neurons in the hidden layers. After the learning process was completed, the weights of connections between neurons were analyzed and units with very low connection weights were eliminated. On the test set, the quality of each thus obtained neural network was checked and the optimal network was selected for prediction. The SNNSv4.2 (Stuttgart Neural Network Simulator) software used at work has no limitations on the multi-layer neural network architecture with backpropagation. Taking into account the fact that the input data set had only 15 elements and the assumption that the tested properties of LWC should be continuous functions, the network was limited to a network with two hidden layers.

In order to obtain the optimal number of neurons in each hidden layer, the same method was used for a given ANN architecture, performing repetitions for each of the ten training and test data sets. The optimal ANN architecture was obtained as 2-11-15-1 during the prediction of density, i.e., two input neurons with shares of GEGA $2 \mathrm{~mm}$ and GEGA $4 \mathrm{~mm}$, eleven neurons in the first hidden layer, fifteen neurons in the second hidden layer and one output neuron as density. In the case of properties such as porosity and compressive strength the best results were achieved by the ANN with the same architecture, while in the case of predicting thermal conductivity the optimal architecture of the 2-7-3-1 type was established.

\section{Results}

The results of properties laboratory tests of LWC for various shares of lightweight aggregate, were presented in Table 4.

During the training of the neural network, the cross-validation procedure was used. Thirteen measurement data on which the network was trained were selected at random, and the quality of prediction was verified on the other two points. This procedure was repeated 10 times on different 13 element subsets. Usually, it is assumed that the test 
set contains $15 \%$ of the elements, the validation set $15 \%$ of the available data set. In the analyzed cases, the reduction in the size of the training set generated a non-linear increase in prediction errors (probably due to a relatively large change in compression strength and porosity depending on the share of additives in LWC), therefore only the test set was used. The ANN with two hidden layers was trained by multiple feeding of the training dataset to the ANN's input, until the stabilization of the total mean square error of the network at a very low level while avoiding the phenomenon of ANN overfitting. Overfitting was partially eliminated by completing the learning process at the initial stage of the mean square error stabilization. Moreover, the small number of points in the training set and their topological distance in the set of parameters (additive shares) meant that the neural network did not "learn" local rapid changes in the analyzed dependence.

Table 4. The LWC laboratory test results.

\begin{tabular}{|c|c|c|c|c|c|c|}
\hline LWC & $\begin{array}{l}\text { Share of GEGA } \\
2 \mathrm{~mm}(\%)\end{array}$ & $\begin{array}{c}\text { Share of GEGA } \\
4 \mathrm{~mm} \mathrm{( \% )}\end{array}$ & $\begin{array}{l}\text { Density } \\
\left(\mathrm{kg} / \mathrm{m}^{3}\right)\end{array}$ & $\begin{array}{c}\text { Porosity } \\
(\%)\end{array}$ & $\begin{array}{c}\text { Compressive } \\
\text { Strength (MPa) }\end{array}$ & $\begin{array}{c}\text { Thermal Conductivity } \\
\lambda(\mathrm{W} / \mathrm{m} \cdot \mathrm{K})\end{array}$ \\
\hline 1 & 0 & 0 & 1560 & 20.8 & 18.65 & 0.8113 \\
\hline 2 & 25 & 0 & 1378 & 17.7 & 21.35 & 0.5886 \\
\hline 3 & 50 & 0 & 1177 & 16.0 & 13.43 & 0.4164 \\
\hline 4 & 75 & 0 & 877 & 22.1 & 3.72 & 0.2827 \\
\hline 5 & 0 & 100 & 1078 & 67.0 & 12.49 & 0.2268 \\
\hline 6 & 0 & 75 & 1028 & 45.0 & 4.59 & 0.4054 \\
\hline 7 & 25 & 50 & 1058 & 27.4 & 4.29 & 0.3114 \\
\hline 8 & 25 & 25 & 1117 & 24.0 & 10.1 & 0.4150 \\
\hline 9 & 25 & 75 & 929 & 65.9 & 4.21 & 0.2106 \\
\hline 10 & 50 & 50 & 903 & 26.4 & 5.44 & 0.2018 \\
\hline 11 & 50 & 25 & 1041 & 20.1 & 6.99 & 0.2954 \\
\hline 12 & 0 & 50 & 1059 & 36.6 & 5.38 & 0.4233 \\
\hline 13 & 0 & 25 & 1304 & 25.6 & 8.92 & 0.6345 \\
\hline 14 & 75 & 25 & 1060 & 19.3 & 6.37 & 0.1709 \\
\hline 15 & 100 & 0 & 1002 & 15.2 & 6.86 & 0.1990 \\
\hline
\end{tabular}

The results of the forecasted by the ANN: density, porosity, compressive strength, and thermal conductivity of LWC as a function of shares of GEGA $2 \mathrm{~mm}$, GEGA $4 \mathrm{~mm}$ and shares of GEGA $2 \mathrm{~mm}$ and GAA $8 \mathrm{~mm}$ in the specimen are presented as $2 \mathrm{D}$ charts in Figure $4 \mathrm{a}-\mathrm{h}$.

In Figure 4 shows, only thermal conductivity behaves in a way that shows a fairly regular evolution between extreme aggregate ratios. Other measured quantities do not show this behavior and if we want to carry out multi-criteria optimization, it is worth using ANN. For example, to select such a composition of aggregates to obtain lightweight concrete with about specified thermal insulation properties. The results of the relationship between density and porosity during laboratory tests are presented in Figure 5a. The predicted results of this relationship with the use of ANN are shown in Figure 5b. Figures 6a and 7a show the results of laboratory tests of the thermal conductivity coefficient as a function of the LWC porosity and density, respectively, while Figures $6 \mathrm{~b}$ and $7 \mathrm{~b}$ show the predicted results obtained by ANN. 


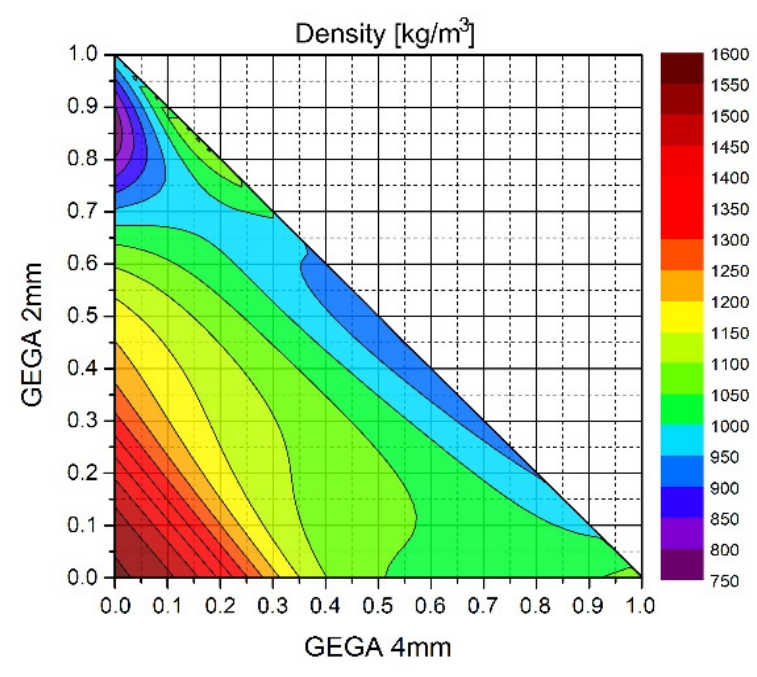

(a)

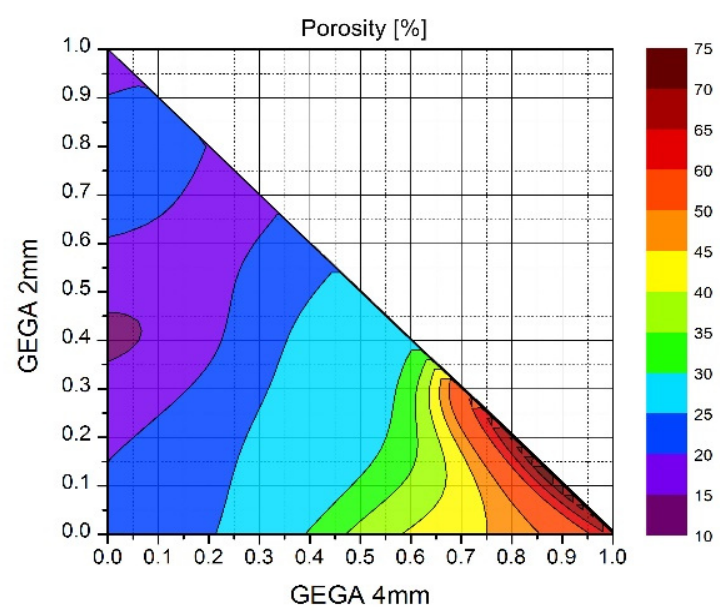

(c)

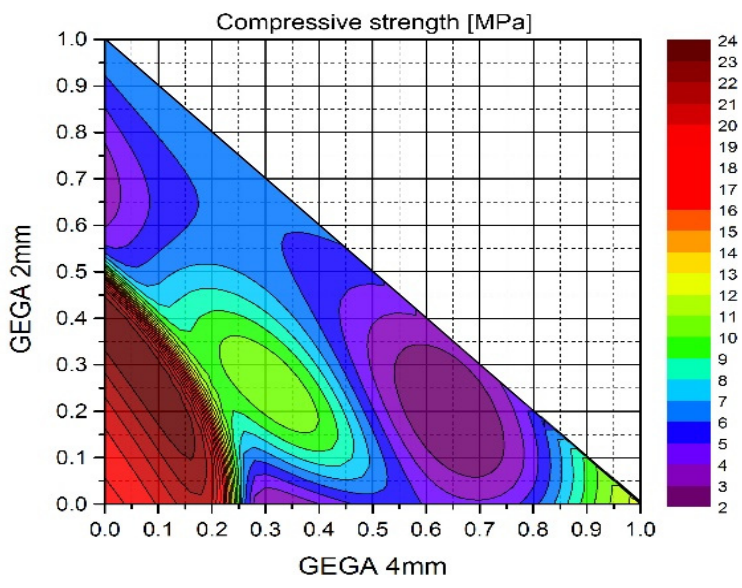

(e)

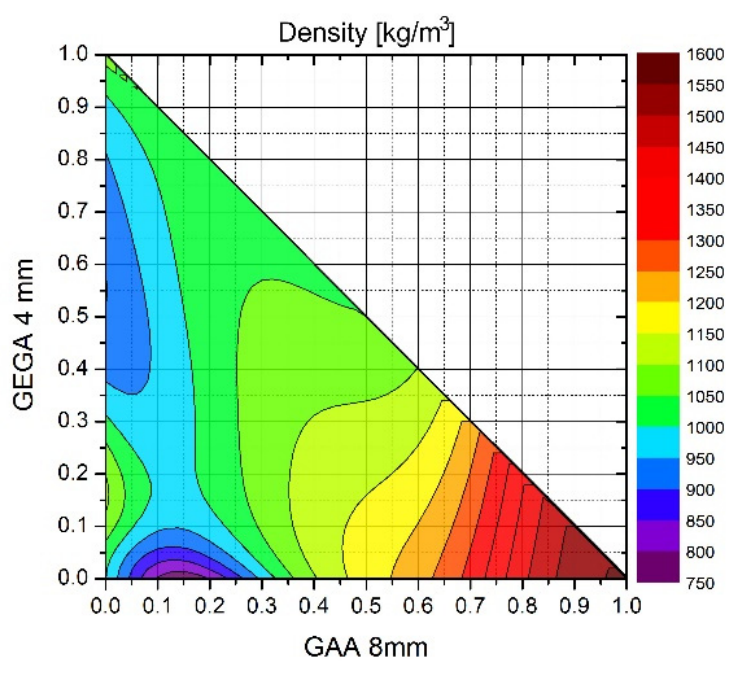

(b)

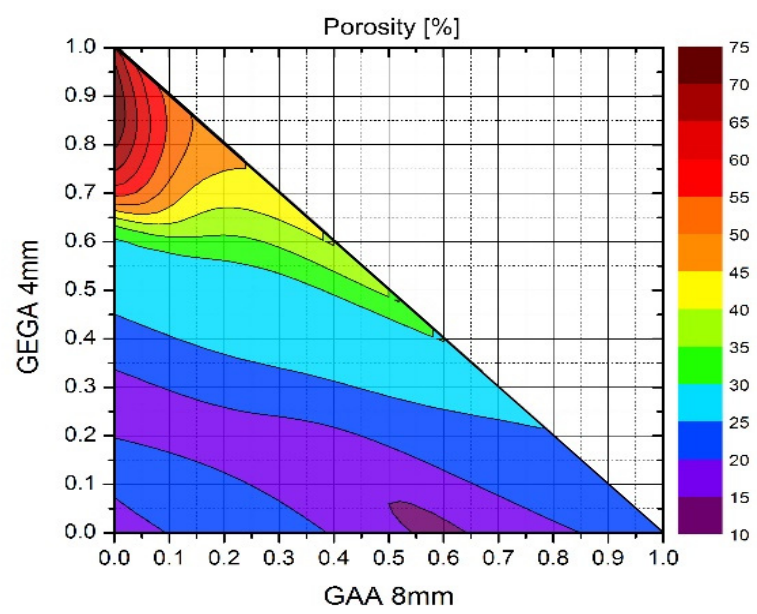

(d)

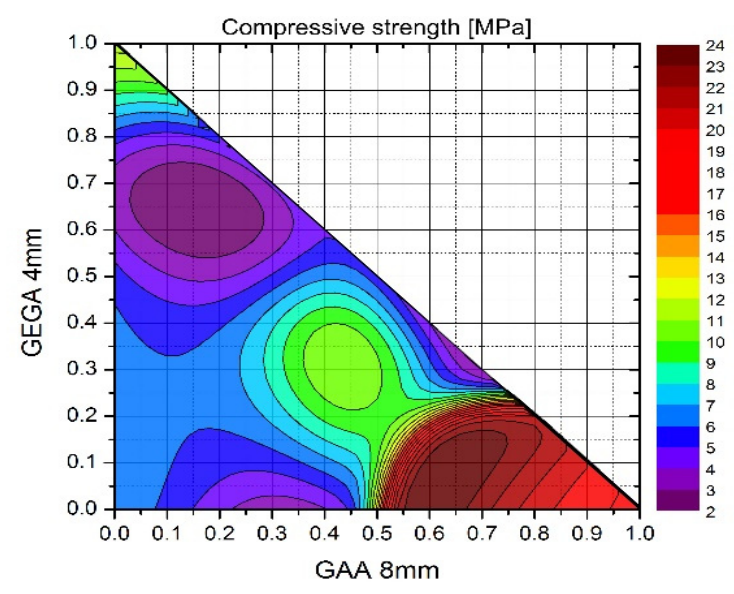

(f)

Figure 4. Cont. 


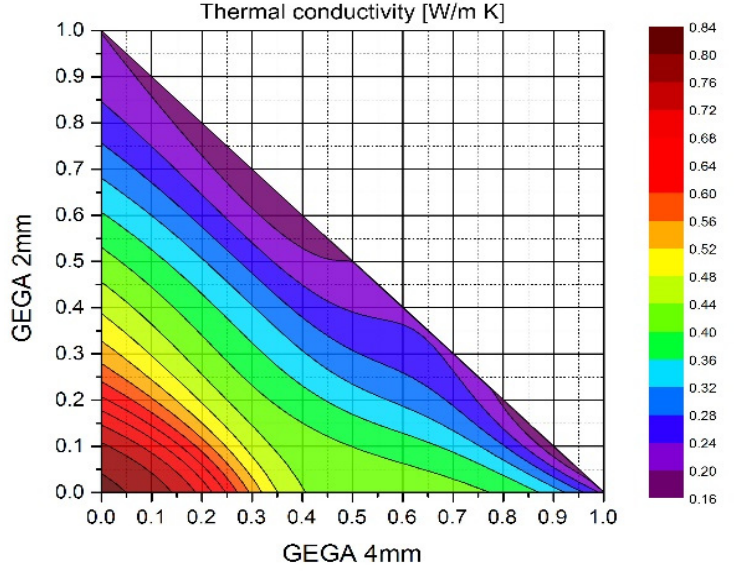

(g)

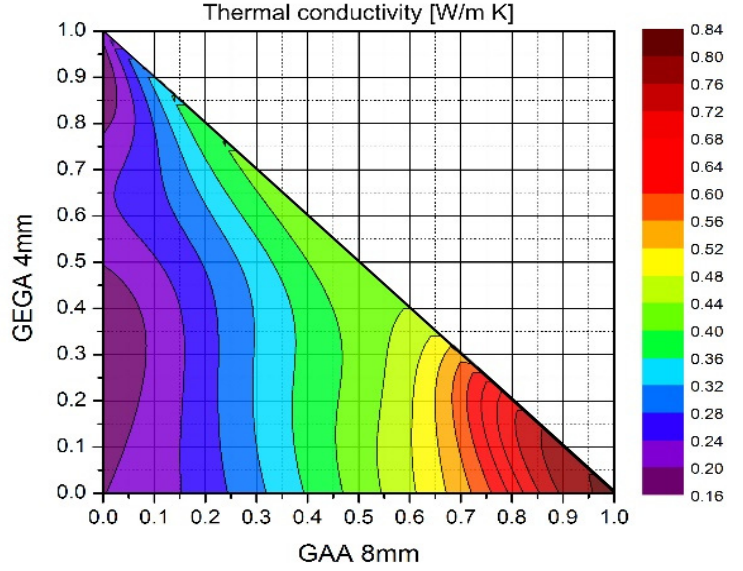

(h)

Figure 4. Graphical presentation of the results obtained by means of ANN method as a function of LWA share. Predicted results for: $(\mathbf{a}, \mathbf{b})$ density in $\left(\mathrm{kg} / \mathrm{m}^{3}\right),(\mathbf{c}, \mathbf{d})$ porosity in $(\%),(\mathbf{e}, \mathbf{f})$ compressive strength in $(\mathrm{MPa}),(\mathbf{g}, \mathbf{h})$ thermal conductivity in $(\mathrm{W} / \mathrm{m} \cdot \mathrm{K})$, respectively.

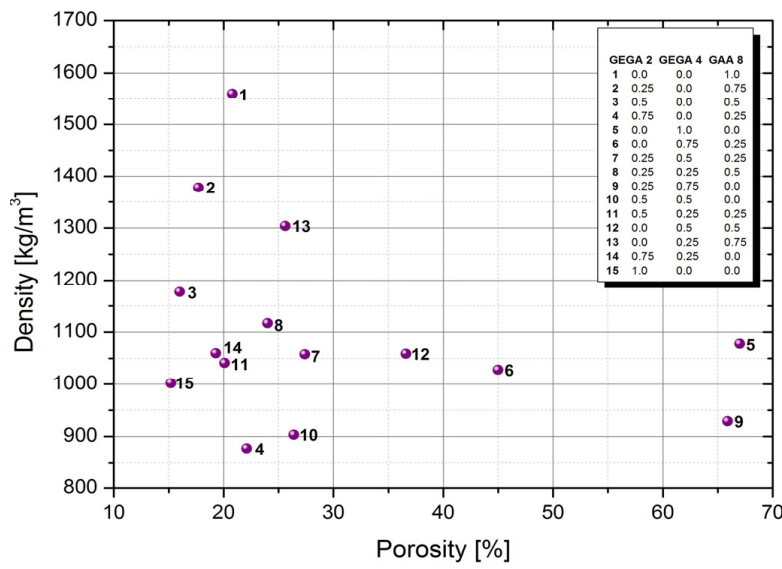

(a)

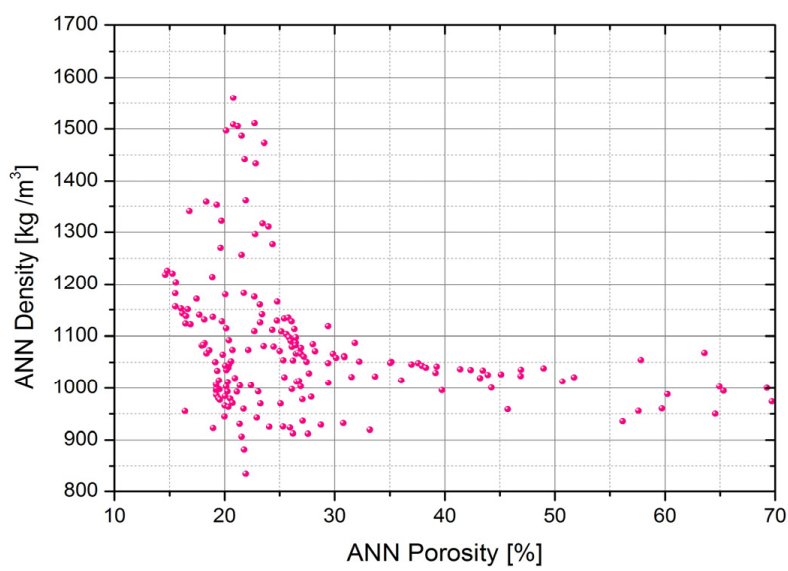

(b)

Figure 5. Graphical presentation of the relationship between density and porosity of the LWC based on: (a) the laboratory test results, (b) the ANN prediction.

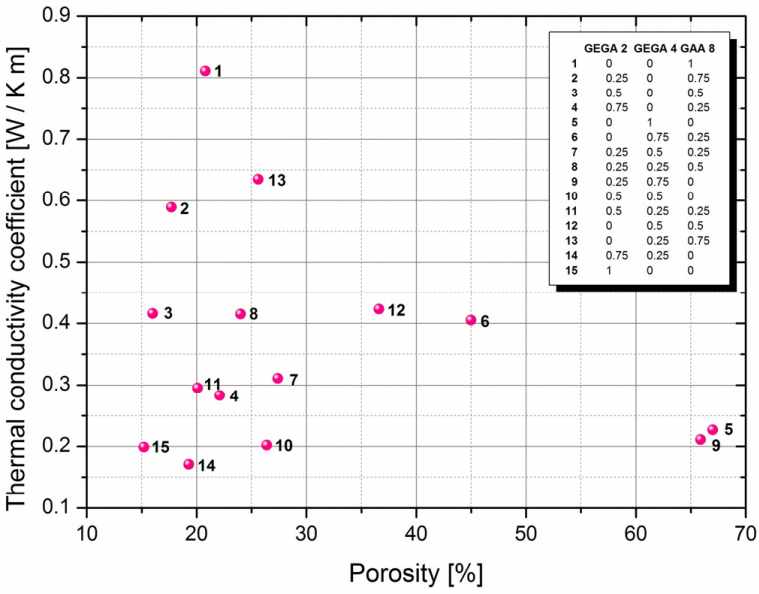

(a)

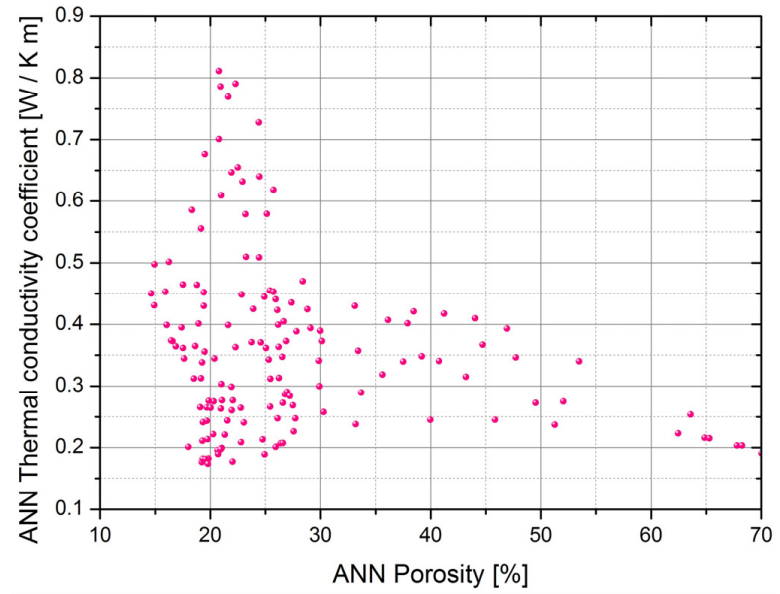

(b)

Figure 6. Graphical presentation of the relationship between the thermal conductivity coefficient and porosity of the LWC based on: (a)the laboratory test results; (b) the ANN prediction. 


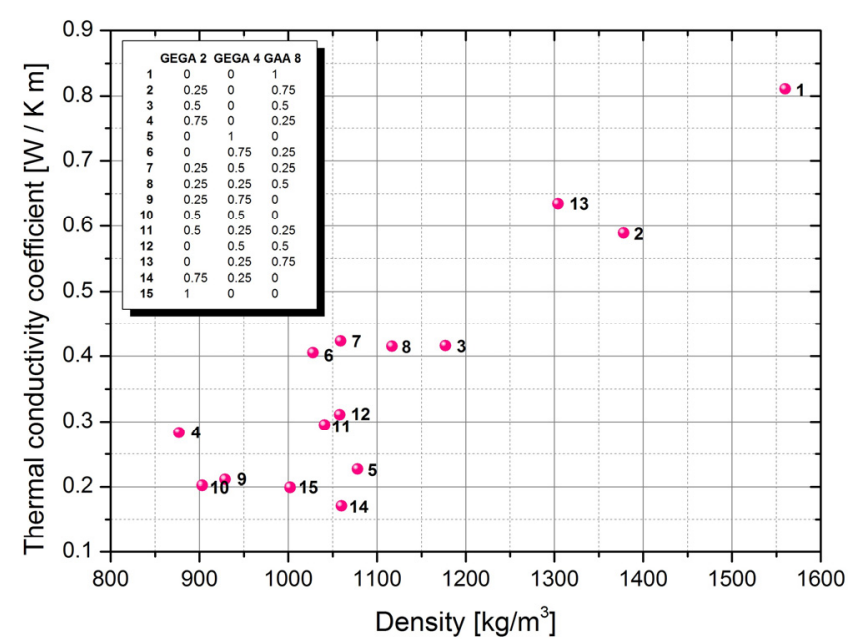

(a)

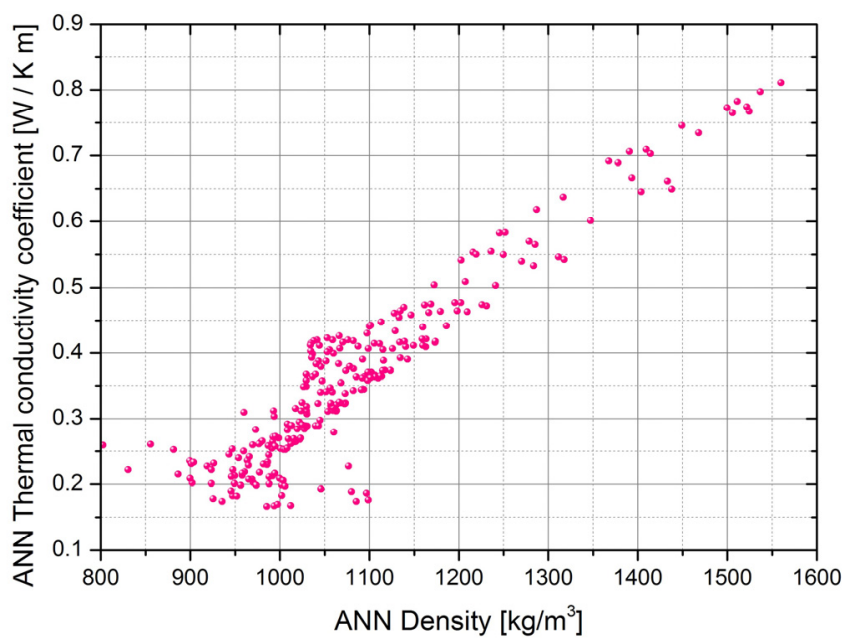

(b)

Figure 7. Graphical presentation of the relationship between the thermal conductivity coefficient and density of the LWC based on: (a) laboratory test results; (b) ANN prediction.

\section{Discussion}

Based on the results of LWC laboratory tests, it can be concluded that the porosity and strength of the LWA grains have a significant impact on the physical properties of the LWC, such as: density, porosity, compressive strength and thermal conductivity. In the case of using of two different types of LWA, the grain structure has the main influence, especially the volume of open and closed pores in the grain volume. GAA grain has a higher crushing strength, although the porosity of GAA grain $(37 \%)$ is similar to that of GEGA grain $(37-42 \%)$. However, the pore structure and arrangement of the pores in the grain matrix of lightweight aggregate are completely different. The presence of GAA aggregate with increased strength has a significant positive effect on the compressive strength of the LWC. The higher the content of GAA, the higher the compressive strength of LWC. However, the highest strength was achieved with a ratio of GAA $8 \mathrm{~mm}$ to GEGA $2 \mathrm{~mm}$ of 1:3, because it is necessary to fill the space between the grains aggregate of a size with a diameter $8 \mathrm{~mm}$. Beneficial values of LWC compressive strength were obtained with the use of aggregate GEGA $2 \mathrm{~mm}$ in the amount of $25 \%$ of the total volume of the aggregate was and if the share of GAA was $75 \%$. If the GAA share was $100 \%$, a $12.6 \%$ decrease in compressive strength LWC was noted. This is due to the impossibility of maximum content of aggregate grains with the diameter of $8 \mathrm{~mm}$ and construction of a porosity skeleton $(20.8 \%)$. In the other use of GEGA $4 \mathrm{~mm}$ grains in the amount of $25 \%$ instead of GEGA $2 \mathrm{~mm}$ of $25 \%$ resulted in an increase in porosity about $7.9 \%$ in LWC (43\%) and a decrease in compressive strength about $58.2 \%$. This replacement also did not have a positive effect on the thermal insulation of the lightweight composite. The lowest thermal conductivity coefficient $(0.17 \mathrm{~W} / \mathrm{m} \cdot \mathrm{K})$ was obtained when GAA aggregate was not used, but only a mixture of GEGA $2 \mathrm{~mm}(75 \%)$ and GEGA $4 \mathrm{~mm}(25 \%)$ aggregates.

Summarizing the analysis, it can be concluded that the highest compressive strength is achieved by cement lightweight composites containing 50, 75 and 100\% GAA $8 \mathrm{~mm}$ and a maximum of $25 \%$ GEGA $2 \mathrm{~mm}$. Lower compressive strength test results were observed for samples containing aggregates with the highest porosity and the lowest compressive strength when using $50 \%, 75 \%$ or $100 \%$ GEGA $4 \mathrm{~mm}$. It can be concluded that a higher GEGA content with a grain size greater than $4 \mathrm{~mm}$ will reduce the compressive strength of the LWC. The higher the proportion of GEGA with a grain size greater than $4 \mathrm{~mm}$, the higher the porosity and the lower the thermal conductivity. For a detailed analysis of LWC properties in the context of using the optimize of mixing ratio of light aggregates with different properties, trained ANN can be used with very good results. The results can be saved as a formula or a graph (Figure $4 a-c$ ). For example, it is possible to make a proposal 
LWC composition of minimum thermal conductivity for a range of density or porosity as shown in Figure $4 \mathrm{~g}, \mathrm{~h}$. The analysis of the selection of the LWA mixing ratio with the use of ANN confirmed that the participation of GAA $8 \mathrm{~mm}$ had the greatest influence on mechanical properties of the lightweight composite, as presented the Figure $4 \mathrm{f}$. While the content of GEGA aggregates in various proportions had an influence on the physical properties such as porosity and thermal conductivity and this presented on Figure $4 \mathrm{c}, \mathrm{d}, \mathrm{g}, \mathrm{h}$. On the Figure $4 \mathrm{a}, \mathrm{b}$ it is visible that the greatest density values were located around the point $(0,0)$, which means, those with a low content of GEGA $2 \mathrm{~mm}$ and GEGA $4 \mathrm{~mm}$. Figure 5 presents the relationship between density and porosity of the LWC based on laboratory test results and ANN prediction, respectively. This dependence is valid only to LWC with GEGA and GAA additives. As it can be seen from the figure, this relationship is very complicated, and it is difficult to propose an analytical formula for the entire range of parameters. This effect is probably due to the random size distribution of the aggregates added to the LWC and their local neighborhood with a varied topological structure. It is also important whether they are closed or open volume aggregates. Therefore, for the values of interest between the measurement points, it is worth using prediction of the results generated by the ANN. Figures 6 and 7 present plots of thermal conductivity as a function of porosity and density of the LWC based on laboratory test results and ANN prediction, respectively. This dependence is valid only to LWC with GEGA and GAA additives. As for the relationship between density and porosity, the analytical relationship between thermal conductivity and porosity cannot be reasonably proposed. However, in the case of the dependence of thermal conductivity on density, a roughly linear relationship between these quantities is visible. This relationship can be approximated by another class of functions (e.g., logistic function, polynomial of degree 3 ) in order to obtain a better fit for small densities, however, it seems more correct to use the ANN prediction.

Based on the analysis test results it was found that ANN is a useful tool for designing of LWC not only with specific mechanical parameters, but also with specific physical properties such as density and thermal insulation.

\section{Conclusions}

The presented results prove that the use of computer tools in concrete technology opens up new design possibilities. Additional benefits of using SNN include the possibility of designing the LWC composition with high precision, optimizing the composition while at the same time predicting the properties of the cement composite not only in terms of compressive strength but also in determining the thermal conductivity coefficient, generally difficult to test. It should be emphasized that the correct use of ANN to design new LWC structures should be preceded laboratory tests, because research results are extremely important for a complete understanding of the LWC design process. However, attention should be paid to the superiority of analytical methods over purely experimental ones. In order to propose an appropriate theoretical model (mathematical, geometric) for designing the composition of a concrete mix, it is necessary to simplify the actual conditions, select the essential features and principles of operation of the phenomenon or object. However, it should be noted that the model is not an exact representation of the modelled system or object and therefore should be properly calibrated. Calibration is also necessary when modifying parameters or introducing new variables based on a series of specific laboratory tests. The advantage of the presented methodology is that when designing a concrete mix, many additional parameters can be introduced, and ANN will have to recognize the relationships between input data and forecast their impact on the final result.

The presented case of using ANN to predict the properties of the LWC may be useful for the development of LWC and NWC new design methods. In addition, this modelling and forecasting method can be used not only for optimizing the selection of aggregate percentages, but also for other components such as the optimization of the amount of cement vs. additives partially replacing the binder. An issue worth considering for next 
new work is analysis of using different types of cements and additives. The test results and their analysis show significant benefits of using ANN to predict LWC properties when the properties of the components are known. As a result, it is also possible to design a specific LWC composition with the desired properties. For example, using multi-criteria optimization methods, it is possible to propose an LWC composition with the lowest possible density and thermal conductivity at a known size compressive strength. Further research may evaluate the use of components other than those described in this article.

Author Contributions: Conceptualization, M.K. and L.K.; methodology, M.K., L.K., T.M. and M.B.; software, L.K.; validation, M.K. and L.K.; formal analysis, M.K.; investigation, M.K.; resources, M.K.; data curation, M.K.; writing-original draft preparation, M.K.; writing—review and editing, M.K.; visualization, M.K. and L.K.; supervision, L.K.; project administration, M.K.; funding acquisition, M.K. All authors have read and agreed to the published version of the manuscript.

Funding: This research received no external funding.

Institutional Review Board Statement: Not applicable.

Informed Consent Statement: Not applicable.

Data Availability Statement: Not applicable.

Acknowledgments: To Filip Kurpiński, Gdańsk University of Technology, Faculty of Electrical and Control Engineering student for help in preparing materials for the manuscript.

Conflicts of Interest: The authors declare no conflict of interest.

\section{References}

1. Bumanis, G.; Bajare, D.; Korjakins, A. Mechanical and Thermal Properties of Lightweight Concrete Made from Expanded Glass. J. Sustain. Archit. Civ. Eng. 2013, 2, 26-32. [CrossRef]

2. Chen, G.; Li, F.; Jing, P.; Geng, J.; Si, Z. Effect of pore structure on thermal conductivity and mechanical properties of autoclaved aerated concrete. Materials 2021, 14, 339. [CrossRef]

3. Adhikary, S.K.; Rudžionis, Ž.; Vaičiukynienè, D. Development of flowable ultra-lightweight concrete using expanded glass aggregate, silica aerogel, and prefabricated plastic bubbles. J. Build. Eng. 2020, 31, 101399. [CrossRef]

4. Kurpińska, M.; Karwacki, J.; Maurin, A.; Kin, M. Measurements of thermal conductivity of LWC cement composites using simplified laboratory scale method. Materials 2021, 14, 1351. [CrossRef] [PubMed]

5. Cabeza, L.F.; Navarro, L.; Pisello, A.L.; Olivieri, L.; Bartolomé, C.; Sanchez, J.; Álvarez, S.; Tenorio, J.A. Behaviour of a concrete wall containing micro-encapsulated PCM after a decade of its construction. Sol. Energy 2020, 200, 108-113. [CrossRef]

6. Cavalline, T.L.; Castrodale, R.W.; Freeman, C.; Wall, J. Impact of lightweight aggregate on concrete thermal properties. ACI Mater. J. 2017, 114, 945-956. [CrossRef]

7. Davraz, M.; Koru, M.; Akdağ, A.E. The Effect of Physical Properties on Thermal Conductivity of Lightweight Aggregate. Procedia Earth Planet. Sci. 2015, 15, 85-92. [CrossRef]

8. Bessonov, I.V.; Bulgakov, B.I.; Zhukov, A.D.; Gradov, V.A.; Ivanova, N.A.; Kodzoev, M.-B.K. Lightweight concrete based on crushed foam glass aggregate. IOP Conf. Ser. Mater. Sci. Eng. 2021, 1083, 012038. [CrossRef]

9. Lesovik, V.S.; Volodchenko, A.A.; Glagolev, E.S.; Chernysheva, N.V.; Lashina, I.V.; Feduk, R.S. Theoretical backgrounds of non-tempered materials production based on new raw materials. IOP Conf. Ser. Mater. Sci. Eng. 2018, 327, 042064. [CrossRef]

10. Tandiroglu, A. Temperature-dependent thermal conductivity of high strength lightweight raw perlite aggregate concrete. Int. J. Thermophys. 2010, 31, 1195-1211. [CrossRef]

11. Yousefi, A.; Tang, W.; Khavarian, M.; Fang, C.; Wang, S. Thermal and mechanical properties of cement mortar composite containing recycled expanded glass aggregate and nano titanium dioxide. Appl. Sci. 2020, 10, 2246. [CrossRef]

12. Shi, J.; Liu, Y.; Liu, B.; Han, D. Temperature Effect on the Thermal Conductivity of Expanded Polystyrene Foamed Concrete: Experimental Investigation and Model Correction. Adv. Mater. Sci. Eng. 2019, 2019, 8292379. [CrossRef]

13. Kurpinska, M.; Grzyl, B.; Kristowski, A. Cost analysis of prefabricated elements of the ordinary and lightweight concrete walls in residential construction. Materials 2019, 12, 3629. [CrossRef] [PubMed]

14. Kurpińska, M.; Haustein, E. Experimental Study of the Resistance to Influence of Aggressive Liquids on Lightweight Concrete. Materials 2021, 14, 4185. [CrossRef]

15. Kurpińska, M.; Ferenc, T. Experimental and numerical investigation of mechanical properties of light weight concretes (LWCs) with various aggregates. Materials 2020, 13, 3474. [CrossRef]

16. Thienel, K.-C. Gefügedichter und Haufwerksporiger Leichtbeton; Der Bundeswehr Universität München: Munich, Germany, 2018.

17. Tavakkol, S.; Alapour, F.; Kazemian, A.; Hasaninejad, A.; Ghanbari, A.; Ramezanianpour, A.A. Prediction of lightweight concrete strength by categorized regression, MLR and ANN. Comput. Concr. 2013, 12, 151-167. [CrossRef] 
18. Chandwani, V.; Agrawal, V.; Nagar, R.; Singh, S. Modeling slump of ready mix concrete using artificial neural network. Int. J. Technol. 2015, 6, 207-216. [CrossRef]

19. Chopra, P.; Sharma, R.K.; Kumar, M. Prediction of Compressive Strength of Concrete Using Artificial Neural Network and Genetic Programming. Adv. Mater. Sci. Eng. 2016, 2016, 7648467. [CrossRef]

20. Fidan, S.; Oktay, H.; Polat, S.; Ozturk, S. An Artificial Neural Network Model to Predict the Thermal Properties of Concrete Using Different Neurons and Activation Functions. Adv. Mater. Sci. Eng. 2019, 2019, 3831813. [CrossRef]

21. Sonebi, M.; Cevik, A. Prediction of Fresh and Hardened Properties of Self-Consolidating Concrete Using Neurofuzzy Approach. J. Mater. Civ. Eng. 2009, 21, 672-679. [CrossRef]

22. Tosee, S.V.R.; Nikoo, M. Neuro-fuzzy systems in determining light weight concrete strength. J. Cent. South Univ. 2019, 26, 2906-2914. [CrossRef]

23. Aneja, S.; Sharma, A.; Gupta, R.; Yoo, D.Y. Bayesian regularized artificial neural network model to predict strength characteristics of fly-ash and bottom-ash based geopolymer concrete. Materials 2021, 14, 1729. [CrossRef] [PubMed]

24. Gupta, S. Using Artificial Neural Network to Predict the Compressive Strength of Concrete containing Nano-silica. Civ. Eng. Archit. 2013, 1, 96-102. [CrossRef]

25. EN 197-1:2011 Cement. Composition, Specifications and Conformity Criteria for Common Cements. Available online: http: / / www.puntofocal.gov.ar/notific_otros_miembros/mwi40_t.pdf (accessed on 7 November 2021).

26. EN 12350-2:2019 Testing Fresh Concrete. Slump-Test. Available online: https://standards.iteh.ai/catalog/standards/cen/cf0e051 1-2176-454c-948d-9e515f3a03f1/en-12350-2-2019 (accessed on 7 November 2021).

27. EN 206:2013+A1:2016 Concrete. Requirements, Properties, Manufacturing Compatibility. [Online]. Available online: https: / / www.techstreet.com/standards/bs-en-206-2013-a1-2016?product_id=1936327 (accessed on 7 November 2021).

28. EN 12350-1:2019 Testing Fresh Concrete. Sampling and Common Apparatus. [Online]. Available online: https:/ civilnode.com/ download-standard/10677746504383/bs-en-12350-12019-testing-fresh-concrete-part-1-sampling-and-common-apparatus (accessed on 7 November 2021).

29. EN 12390-4:2019 Testing Hardened Concrete. Compressive Strength. Specification for Testing Machines. Available online: https://standards.iteh.ai/catalog/standards/cen/10b1c613-819b-42d7-8f94-480cd37a666a/en-12390-4-2019 (accessed on 7 November 2021).

30. Lee, N.K.; Souri, H.; Lee, H.K. Neural Network Application Overview in Prediction of Properties of Cement-Based Mortar and Concrete. In Proceedings of the 2014 World Congress on Advances in Civil Environmental and Materials Research, Busan, Korea, 24-28 August 2014.

31. Kaplan, G.; Yaprak, H.; Memiş, S.; Alnkaa, A. Artificial neural network estimation of the effect of varying curing conditions and cement type on hardened concrete properties. Buildings 2019, 9, 10. [CrossRef]

32. Divyah, N.; Thenmozhi, R.; Neelamegam, M. Strength properties and durability aspects of sintered-fly-ash lightweight aggregate concrete. Mater. Tehnol. 2020, 54, 301-310. [CrossRef]

33. Nehdi, M.; el Chabib, H.; el Naggar, M.H. Predicting performance of self-compacting concrete mixtures using artificial neural networks. ACI Mater. J. 2001, 98, 394-401. [CrossRef]

34. Ozturan, M.; Kutlu, B.; Ozturan, T. Comparison of concrete strength prediction techniques with artificial neural network. Build. Res. J. 2008, 56, 23-36.

35. Pinkus, A. Approximation theory of the MLP model in neural networks. Acta Numer. 1999, 8, 143-195. [CrossRef]

36. Kurpinska, M.; Kułak, L. Predicting performance of lightweight concrete with granulated expanded Glass and Ash aggregate by means of using Artificial Neural Networks. Materials 2019, 12, 2002. [CrossRef]

37. Meir, R.; Maiorov, V.E. On the optimality of neural-network approximation using incremental algorithms. IEEE Trans. Neural Netw. 2000, 11, 323-337. [CrossRef] 